\title{
A review of bovine cases consigned under veterinary certification to emergency and casualty slaughter in Ireland during 2006 to 2008
}

Mary Cullinane ${ }^{1 \star}$ Edmond O’Sullivan², Gerald Collins ${ }^{3}$, Daniel M. Collins ${ }^{4}$ and Simon J. More ${ }^{4}$

1. Department of Agriculture Fisheries and Food, District Veterinary Office Cork North, Hibernian House, South Mall, Cork, Ireland

?. Veterinary Department, Cork County Council, County Hall, Cork, Ireland

3. Department of Agriculture, Fisheries and Food, Veterinary Public Health, Southern Division, Connolly Hall, Lapps Quay, Cork, Ireland

${ }^{4}$. Centre for Veterinary Epidemiology and Risk Analysis, UCD School of Agriculture, Food Science and Veterinary Medicine, University College Dublin, Belfield, Dublin 4, Ireland

* Corresponding author: Mary Cullinane. Tel: +353 86850 6417; Fax: +353 21427 4009;

email: mary.cullinane@agriculture.gov.ie

\section{KEY WORDS}

Ireland, emergency slaughter, casualty slaughter, cattle, veterinary certification.

\section{ABSTRACT}

The emergency and casualty slaughter of cattle for human consumption (in cases where animals are likely to have suffered from acute or chronic pain, respectively) in Ireland requires that the animal is accompanied to the slaughterhouse by an official veterinary certificate (VC) completed on-farm by the owner's private veterinary practitioner (PVP). No published data is currently available in Ireland based on information provided in these VCs. In this paper, we present a review of bovine cases consigned under veterinary certification to emergency and casualty slaughter in Ireland during 2006 to 2008 . All VCs during the years 2006 (where available), 2007 and 2008 were collected from four large Irish slaughterhouses. The data were computerized, and analysed using descriptive and spatial methods. In total, 1,255 VCs were enrolled into the study (1,255 study animals, 1,072 study herds), 798 (63.6\%) and 457 (36.4\%) animals were consigned to emergency and casualty slaughter, respectively. VCs were completed throughout the year, with consigned animals travelling a mean distance of $27.2 \mathrm{~km}$ from farm to slaughter. The time elapsed between veterinary certification and slaughter was greater than three days for $18.2 \%$ of all study animals. In 965 (76.9\%) animals, the certified suspected disability related to the locomotory system, most commonly as a result of fractures. Among animals for which data were available, $11.9 \%$ were totally condemned at post-mortem. The transport of animals with fractured limbs and/or other painful conditions is a significant animal welfare concern.

\section{INTRODUCTION}

The beef industry is an important sector of the Irish economy. During 2006 to 2008, approximately 1.6 million (from a national herd of 6 million) cattle were slaughtered annually for human consumption. Approximately $85 \%$ of Irish beef is exported, to a value of $€ 1.7$ billion annually, accounting for about $20 \%$ of total agri-food exports (DAFF 2007, 2008, 2009a).

High animal health and welfare standards are essential to ensuring good quality safe food for the consumer. In compliance with current European food safety and animal welfare legislation (Regulation (EC) 854/2004; Regulation (EC) 852/2004; Council Directive 93/119/EC; Council Regulation (EC) 1/2005 and S.I. No. 14 of 2008 EC (The Protection of Farmed Animals Regulations) 2008), all
Irish Veterinary Journal

Volume 63 Number 92010

animals presented for slaughter for human consumption must satisfy two fundamental requirements:

- $\quad$ they must be free from conditions which might adversely affect human or animal health, and

- their welfare must not be compromised at any stage from the farm to the moment of slaughter.

In Ireland, as elsewhere (Roman 2009), the veterinary profession plays an important role in achieving compliance with these requirements (Regulation (EC) No. 854/2004 (Chapter II, Article 5)) and Regulation (EC) No. 882/2004. In the majority of cases, cattle intended for slaughter are both healthy and fit for transport to the slaughterhouse. In the small number of cases when health or fitness for transport is in doubt, animals may, at the discretion of a 
private veterinary practitioner (PVP), be presented for slaughter for human consumption either for emergency or casualty slaughter. Emergency slaughter (ES) relates to otherwise healthy animals that have suffered a physical accident or injury which results in acute pain (for example, a fractured limb), whereas casualty slaughter (CS) relates to animals suffering from more chronic conditions (such as mastitis or chronic arthritis) (DAFF 2009b). In compliance with existing legislation (Regulation (EC) 854/2004 and Regulation (EC) $853 / 2004$ ), emergency and casualty slaughter require that, in cases where the carcass is intended for human consumption, the animal is accompanied to the slaughterhouse by an official veterinary certificate (VC) completed on-farm by the owner's private veterinary practitioner (PVP).

Within the EU and elsewhere, there is limited published data on emergency and casualty slaughter of cattle based on information provided by the VC. There is no published data available from Ireland. In recent Czech studies, Vecerek et al. (2003) and Pistekova et al. (2004) examined the locomotor system of compromised cattle presented for slaughter due to immobility, concluding that measures to limit injury to animals before and during transport and at slaughter would serve to reduce the frequency of ES and carcase condemnation. Kozak et al. (2004) confirmed the locomotory apparatus as the principal reason for ES of pigs, and suggested that immobility was due to injuries resultant from unsuitable handling at farms and during transport rather than inadequate care causing general conditions and other diseases.

In this paper, we present a review of bovine cases consigned under veterinary certification to emergency and casualty slaughter in Ireland during 2006 to 2008.

\section{MATERIALS AND METHODS}

\subsection{The data}

Four large slaughterhouses in the Republic of Ireland were selected for inclusion in this study, on the basis of geographical location and throughput. The slaughterhouses are located in each of the four Irish provinces (Leinster, Munster, Connaught, Ulster), with different catchments and ownership. Each slaughterhouse kills a mix of beef and dairy cattle. Following an approach to the Official Veterinarian (OV) at each slaughterhouse, all VCs during the years 2006 (where available), 2007 and 2008 were collected. Where available, OVs were also asked to provide condemnation data, collected following slaughter, corresponding to each VC.

Following collection, each VC was screened, and subsequently retained for inclusion in the study if the $\mathrm{VC}$ had been issued using the national standard format (Figure 1), and if each of the following data were available and legible: official eartag number (unique to each bovine in Ireland), date issued, veterinary and owner signatures, and the suspected disability as specified by the certifying PVP. Using the official ear-tag

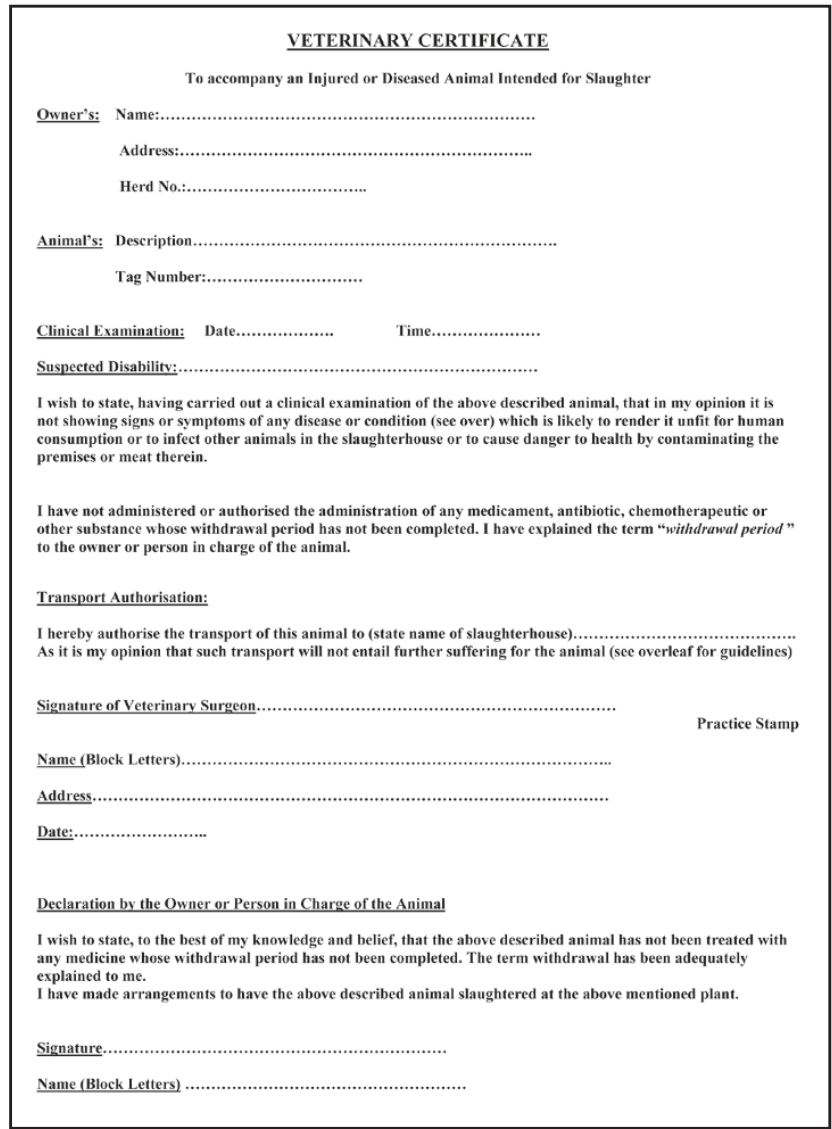

Guidelines for the Ante Mortem Examination

Under the Abattiors Act 1988(Veterinary Examination) Regulations 1992 an animal may be considered to be unfit for slaughter for human consumption if it shows signs or symptoms of a disease, disorder, condition or injury any of the following diseases or condition:

Anthrax;

Acute or chronic septic conditions with systemic disturbance or to an extent sufticient to render meat or offals unfit for food;

Advanced pregnancy;

Bekquarter or Blackleg.

Berne spongiform Encephalopathy;

Imminent death:
Digestive disord

of Animals Act 1966;

Extensive injuries which render meat and offals unfit for food;

Is unsightly, unwholesome or unfit for

food;

excitement or fatigue;

Fever;

Gangrenous conditions unless confined in extent and effect to a small area;

Glanders;

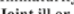

Joint ill or

Mastitis or mammitis whether acute septic or gangrenous:

Milk Fever

Oedema, general and dropsical;

Pneumonia and pleurisy;

Salmonellosis:

Swine fever and swine erysipelas;

Tetanus.

Please ensure that any neurological symptoms manifested by the animal are differentiated from the symptoms of Bovine Spongiform Encephalopathy. Please note that it is a legal requirement to report any Guidelines for Assessing Fitness for Transport

The transport authorisation is a requirement under article 9 of the European Communities (protection of Animals at the Time of Slaughter) Regulations, 1995 .

政 In particular, do not transport:

1) any animal suffering pain;

2) any animal which cannot be loaded or unloaded without using force,

) any animal with severe wounds or protruding viscera.

Where transport is authorised, animals should in all eases be transported to the nearest available

slaughterhouse.

Please note that the above are guidelines only and are not intended to be exhaustive or to be a legal interpretation of the relevant legislation

Figure 1. The Official Veterinary Certificate. [The European Communities (Protection of Animals at the time of Slaughter) Regulations 1995, Regulation 9. Revoked by European Communities (Welfare of Farmed Animals) Regulations 2008]. 
number and two databases managed by the Department of Agriculture, Fisheries and Food (DAFF; Animal Health Computer System, AHCS; Animal Identification and Movement System (AIM), the date of birth and slaughter for each 'study animal' and the identity and primary production system (dairy, beef) of the 'study herd' from which the animal had moved immediately prior to slaughter was established.

\subsection{Data management}

The data were managed using Microsoft Excel (Microsoft Corporation, Redmond, WA, USA). Data entry was conducted manually. Subsequently, approximately $40 \%$ of data entries were cross-checked against the VCs for errors. A coding system was devised to numerically assign each certified suspected disability to a primary injury or other disability, based on body system. Each VC was also categorized as either emergency or casualty slaughter, based on whether the animal was likely to have suffered from acute or chronic pain, respectively. Geographic data were managed using Arcview 3.2 (Environmental Systems Research Institute Inc., Redlands, CA., USA.).

\subsection{Data analysis}

Data analyses, including simple statistical methods, were conducted using Microsoft Excel.

In the Republic of Ireland, the Land Parcel Identification System (LPIS) contains the geo-referenced location of herds which claim European Area Aid. In this study, the centroid of the closest parcel (to the slaughterhouse) of each herd, as it appears on the LPIS database for 2008, was used to represent the location of each study herd. For herds that did not appear on the LPIS database for 2008 (<4\% of study herds), herd location was based on the centroid of the district electoral division (DED) corresponding to the address of the study herd. The distance between each study herd and the corresponding slaughterhouse was calculated using the Distances and Bearings between Matched Features V2.1 extension (Jennes Enterprises, Flagstaff, AZ, USA.).

\section{RESULTS}

Although 1,363 veterinary certificates (VCs) were available, 108 (7.9\%) did not meet the inclusion criteria. Therefore, 1,255 VCs were enrolled into the study; a total of 1,255 study animals from 1,072 study herds (a mean of 1.17 study animals per study herd [minimum 1 , maximum 12, median 1]). Of these, 798 (63.6\%) and 457 (36.4\%) animals were consigned on the basis of emergency and casualty slaughter, respectively.

A description of the study animals, by class (bull, steer, cow, heifer), production system and age, is presented in Table 1. There were 824 (65.8\%) beef and 431 (34.3\%) dairy animals. The dairy animals were predominantly Friesian; the beef animals included Charolais (36.8\%), Limousin (25\%), Aberdeen Angus (13.3\%), both Hereford and Simmental 9\% and other breeds (15.9\%).

VCs were completed throughout the year (Figures 2 and $3)$, being highest in February $(125,10.0 \%)$ and lowest in September $(80,6.4 \%)$. Further, ECs and CSs were conducted throughout the working week (Figures 4), being highest on Wednesday $(285,22.7 \%)$ and lowest on Friday $(187,14.9 \%)$. In total, 422 (33.6\%) animals were slaughtered on the day of certification, and 1,026 (81.8\%) within 2 days of certification. The mean time between certification and slaughter was 3 (minimum 0 , maximum 452, median 1) days. The time between certification and slaughter, by slaughter classification, is presented in Table

Table 1. The number of study animals, by class (bull, steer, cow, heifer), production system and age

\begin{tabular}{|c|c|c|c|c|c|}
\hline \multirow{3}{*}{ Class } & \multicolumn{4}{|c|}{ Production system, age (months) } & \multirow{3}{*}{ Total $(\%)$} \\
\hline & \multicolumn{2}{|c|}{ Beef } & \multicolumn{2}{|c|}{ Dairy } & \\
\hline & $<24$ & $\geq 24$ & $<24$ & $\geq 24$ & \\
\hline Bull & 55 & 76 & 9 & 10 & $150(11.9)$ \\
\hline Steer & 227 & 156 & 76 & 74 & $533(42.5)$ \\
\hline Cow & 5 & 151 & 2 & 183 & 341 (27.1) \\
\hline Heifer & 97 & 57 & 25 & 52 & $231(18.4)$ \\
\hline Total (\%) & $384(30.6)$ & 440 (35.1) & $112(8.9)$ & $319(25.4)$ & 1255 \\
\hline
\end{tabular}

Table 2. The number of days between certification and slaughter of study animals, by slaughter classification (emergency or casualty)

\begin{tabular}{|c|c|c|c|c|c|c|c|c|c|c|c|}
\hline \multirow{2}{*}{$\begin{array}{l}\text { Slaughter } \\
\text { classification }\end{array}$} & \multicolumn{11}{|c|}{ Number of days between certification and slaughter } \\
\hline & $<1$ & 1 & 2 & 3 & 4 & $\begin{array}{l}5 \text { to } \\
<10\end{array}$ & $\begin{array}{l}10 \text { to } \\
<20\end{array}$ & $\begin{array}{l}20 \text { to } \\
<50\end{array}$ & $\begin{array}{c}50 \\
\text { to }<100\end{array}$ & $\geq 100$ & Total (\%) \\
\hline Emergency & 279 & 298 & 88 & 40 & 27 & 36 & 16 & 11 & 2 & 1 & $798(63.6)$ \\
\hline Casualty & 143 & 157 & 61 & 21 & 13 & 26 & 8 & 19 & 5 & 4 & 457 (36.4) \\
\hline Total (\%) & $422(33.6)$ & $455(36.3)$ & 149 (11.9) & $61(4.9)$ & 40 (3.2) & $62(4.9)$ & $24(1.9)$ & $30(2.4)$ & $7(0.6)$ & $5(0.4)$ & 1255 \\
\hline
\end{tabular}




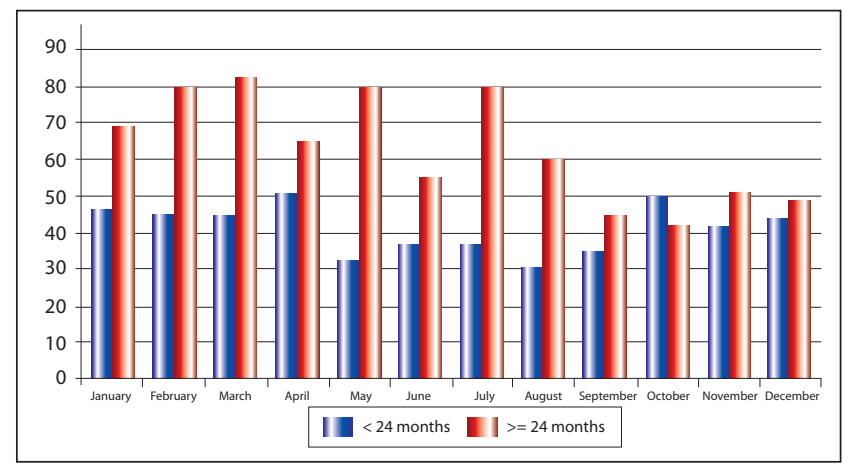

Figure 2 . The number of study animals by age category ( $<24$ months or $\geq 24$ months), presented for emergency or casualty slaughter during each month of the year.

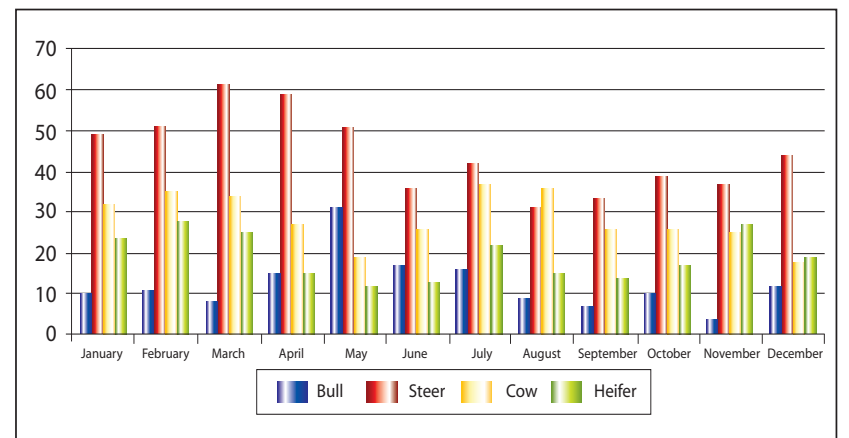

Figure 3. The number of study animals, categorized by class (bull, steer, cow, heifer), presented for emergency or casualty slaughter during each month of the year.

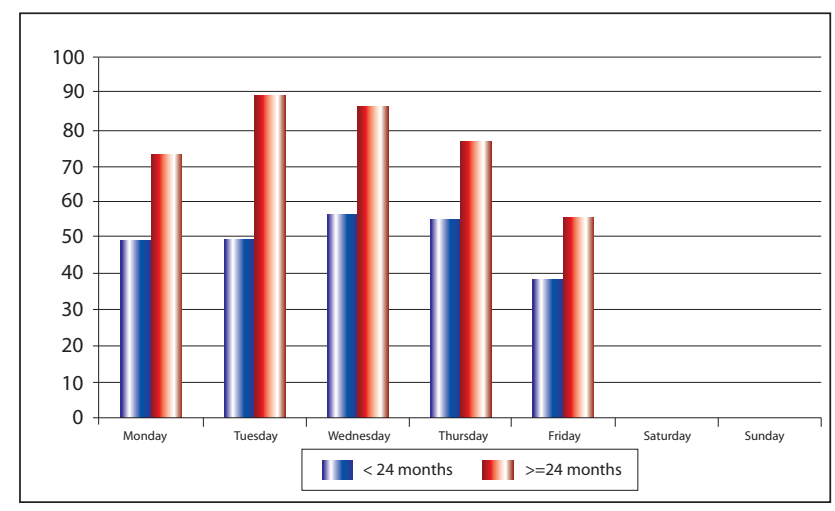

Figure 4. The number of study animals, divided by age category, $(<24$ months or $\geq 24$ months), presented for emergency or casualty slaughter during each day of the week.

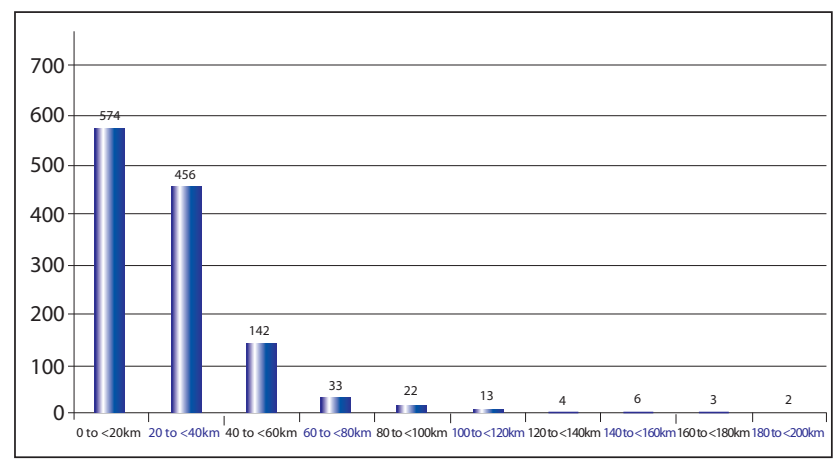

Figure 5. The distribution of distances travelled from the study herd to the corresponding slaughterhouse
2. The mean transport distance between each study farm and the corresponding slaughterhouse was 27.2 (minimum 0.26, maximum 188.0, median 21.8) km. In total, 1,030 (82.1\%) and 1,227 (97.8\%) study animals were transported distances of no more than 40 and $100 \mathrm{~km}$, respectively

(Figures 5).

The certified suspected disability for 965 (76.9\%) study animals was related to the locomotory system (Table 3), most commonly (340, 35.2\% of 965) as a result of fractures. Beef breeds accounted for $74.7 \%$ of the fractures. The time between certification and slaughter, by primary injury or other disability, is presented in Table 4. Condemnation data were available for 463 (36.9\%) animals, including 55 (11.9\% of 463$)$ with total carcase condemnation.

\section{DISCUSSION}

This study was conducted to review bovine cases consigned under veterinary certification to emergency and casualty slaughter of cattle in Ireland during 2006 to 2008 This is a particularly important area for animal welfare, yet few studies of this type have been conducted previously. The results have direct implications for both government and industry in Ireland.

There was an element of subjectivity in the interpretation of the suspected disability section on the VCs as provided by PVPs. In a number of cases, the information was limited e.g. fractured limb; lame; injured leg or recumbent. Other PVPs were more specific in identifying the specific condition and body part affected, however the most useful were those that not only identified the specific condition but also gave the cause e.g. shear grab ( a tractor-mounted silage grab used in feedlots) injury to the right foreleg and left shoulder. These clinical diagnoses were used as the basis for subsequent coding and grouping under primary injury or other disability, based on body system (Table 3). Specific clinical diagnoses may have lead to several injuries, with the potential for misclassification within, but not between, specific body systems. The full set of VCs for 2006 was not available, although there was a representative number for each month of the year. For each study animal, no ante mortem data were available, and post-mortem data were not complete. As a consequence, caution is needed when interpreting aspects of the results.

In this study, most injuries among the study animals were related to the locomotory system. Similar findings are reported by Pistekova et al. (2004), Vecerek et al. (2003) and Broom \& Corke (2002). The majority of these injuries were a result of bone fractures with two thirds occurring in beef animals. This is probably a reflection of reduced handling in beef (as compared to dairy) animals (Grandin 1997). The European Community's Scientific Committee on Animal Health and Welfare (2001) also reported that the beef breeds are associated with hyper-muscularity which 


\begin{tabular}{|c|c|c|c|c|c|c|}
\hline \multirow{3}{*}{$\begin{array}{l}\text { Primary injury or other } \\
\text { disability, based on body system }\end{array}$} & \multicolumn{4}{|c|}{ Production system, age (months) } & \multirow{3}{*}{ Subtotal } & \multirow{3}{*}{ Total (\%) } \\
\hline & \multicolumn{2}{|c|}{ Beef } & \multicolumn{2}{|c|}{ Dairy } & & \\
\hline & $<24$ & $\geq 24$ & $<24$ & $\geq 24$ & & \\
\hline Cardiac & 3 & 3 & 2 & 11 & & $19(1.5)$ \\
\hline Digestive & 13 & 20 & 3 & 36 & & $72(5.7)$ \\
\hline Eye & 2 & 7 & 0 & 4 & & $13(1.0)$ \\
\hline Head & 6 & 8 & 1 & 8 & & $23(1.8)$ \\
\hline Integument & 5 & 9 & 0 & 6 & & $20(1.6)$ \\
\hline Locomotory & 330 & 331 & 93 & 211 & & 965 (76.9) \\
\hline \multicolumn{7}{|l|}{ Fracture/Injury } \\
\hline Foreleg & 39 & 26 & 10 & 21 & 96 & \\
\hline Hindleg & 118 & 82 & 32 & 71 & 303 & \\
\hline Leg (not specified) & 24 & 30 & 12 & 14 & 80 & \\
\hline Spinal/back & 54 & 44 & 20 & 28 & 146 & \\
\hline Hip/pelvic & 31 & 56 & 5 & 28 & 120 & \\
\hline Shoulder & 11 & 10 & 0 & 2 & 23 & \\
\hline \multicolumn{7}{|l|}{ Lameness } \\
\hline Foreleg & 4 & 5 & 1 & 2 & 12 & \\
\hline Hindleg & 18 & 23 & 6 & 12 & 59 & \\
\hline Lame (not specified) & 14 & 19 & 5 & 16 & 54 & \\
\hline Deformed legs & 5 & 3 & 0 & 4 & 12 & \\
\hline Paralysis & 4 & 15 & 0 & 6 & 25 & \\
\hline Spastic paresis & 4 & 3 & 0 & 1 & 8 & \\
\hline Recumbent & 1 & 5 & 0 & 3 & 9 & \\
\hline Other & 3 & 10 & 2 & 3 & 18 & \\
\hline Reproductive & 12 & 41 & 5 & 21 & & $79(6.3)$ \\
\hline Respiratory & 5 & 7 & 3 & 6 & & $21(1.7)$ \\
\hline Other & 8 & 14 & 5 & 16 & & $43(3.4)$ \\
\hline TOTAL (\%) & $\begin{array}{c}384 \\
(30.6)\end{array}$ & $\begin{array}{c}440 \\
(35.1)\end{array}$ & $\begin{array}{c}112 \\
(8.9)\end{array}$ & $\begin{array}{c}319 \\
(25.4)\end{array}$ & & 1255 \\
\hline
\end{tabular}

can cause leg disorders and calving difficulties. In the present study, hind-limb injury (including fracture) was three times more frequent than forelimb injury. Mounting was noted by PVPs as a probable cause on a number of VCs. Interestingly, the tibia was named as the bone involved in a number of VCs; further, during slaughterhouse post-mortem inspections, the tibia (distal) is frequently identified as the fractured bone. An imbalance between rapid growth of bone and development of the musculature of the hindquarters of the young beef animal may also be a factor in hind leg fractures (Scientific Committee on Animal Health and Welfare 2001)

A number of locomotor injuries may be due to farmyard accidents involving machinery, handling facilities or slippery floors. As examples, badly fractured front legs and hindlimb tendon injuries were linked to shear grab accidents, fractured leg to slipping on slats, and neck muscle damage was attributed to a new gate system. White \& Moore (2009) and Stull et al. (2007) each mention that improved farm management, including care with farm machinery, would greatly reduce the incidence of ES/CS animals. Injuries involving other body systems were noted. Although of concern, these were much less common.

The transport of animals with fractured limbs and/or other painful conditions is a significant animal welfare concern. During a recent Food and Veterinary Office (FVO) (DG SANCO 2008) mission, conducted whilst this study was underway, it was found that Ireland was not in compliance with European legislation on the issue of bovine ES/CS slaughter transport. Specifically, a number of VCs had been issued for animals that were not fit for transport to slaughter, including animals with broken legs, pelvic or spinal injuries. This is contrary to article 3(b) and annex 1, chapter 1 of Council Regulation (EC) 1/2005 and to article 12 of Council Directive 93/119/EC. Additionally, in the current study, there were a number of instances where transport distances were excessive (for example, an animal with a fractured femur was transported $185 \mathrm{~km}$, an animal with a fractured hind leg was transported 150 $\mathrm{km}$ and a downer cow injured by a bull was transported 87 


\begin{tabular}{|c|c|c|c|c|c|c|c|c|c|c|c|c|}
\hline \multirow{2}{*}{$\begin{array}{l}\text { Primary injury or other } \\
\text { disability, based on body } \\
\text { system }\end{array}$} & \multicolumn{12}{|c|}{ The number of days between certification and slaughter (days) } \\
\hline & $<1$ & 1 & 2 & 3 & 4 & $\begin{array}{l}5 \text { to } \\
<10\end{array}$ & $\begin{array}{l}10 \text { to } \\
<20\end{array}$ & $\begin{array}{l}20 \text { to } \\
<50\end{array}$ & $\begin{array}{l}50 \text { to } \\
<100\end{array}$ & $\geq 100$ & Subtotal & Tota \\
\hline Cardiac & 6 & 5 & 4 & 1 & & 2 & & 1 & & & & 19 \\
\hline Digestive & 35 & 25 & 3 & 3 & & 4 & & & 2 & & & 72 \\
\hline Eye & 3 & 3 & 4 & 1 & & 1 & & 1 & & & & 13 \\
\hline Head & 11 & 9 & 2 & & 1 & & & & & & & 23 \\
\hline Integument & 8 & 7 & 1 & 1 & 1 & 1 & & 1 & & & & 20 \\
\hline Locomotory & 301 & 357 & 120 & 51 & 35 & 47 & 23 & 22 & 5 & 4 & & 965 \\
\hline \multicolumn{13}{|l|}{ Fracture/Injury } \\
\hline Foreleg & 40 & 38 & 3 & 6 & 3 & 5 & 1 & & & & 96 & \\
\hline Hindleg & 108 & 119 & 38 & 13 & 7 & 14 & 2 & 1 & 1 & & 303 & \\
\hline Leg (not specified) & 29 & 31 & 11 & 4 & & 2 & 3 & & & & 80 & \\
\hline Spinal/back & 42 & 52 & 19 & 10 & 4 & 6 & 6 & 5 & 1 & 1 & 146 & \\
\hline Hip/pelvic & 31 & 43 & 19 & 2 & 8 & 4 & 5 & 8 & & & 120 & \\
\hline Shoulder & 9 & 6 & 1 & 2 & 3 & 2 & & & & & 23 & \\
\hline \multicolumn{13}{|l|}{ Lame } \\
\hline Foreleg & 1 & 6 & 2 & & & 2 & & 1 & & & 12 & \\
\hline Hindleg & 12 & 26 & 6 & 2 & 2 & 3 & 4 & 4 & & & 59 & \\
\hline Lame (not specified) & 17 & 15 & 10 & 3 & 2 & 4 & & 1 & 2 & & 54 & \\
\hline Deformed legs & 1 & 4 & 3 & & & 1 & 1 & 2 & & & 12 & \\
\hline Paralysis & 2 & 9 & 3 & 5 & 2 & 2 & 1 & & 1 & & 25 & \\
\hline Spastic paresis & & 3 & 2 & & 1 & & & & & 2 & 8 & \\
\hline Recumbent & 3 & 2 & 2 & & 1 & 1 & & & & & 9 & \\
\hline Other & 6 & 3 & 1 & 4 & 2 & 1 & & & & 1 & 18 & \\
\hline Reproductive & 36 & 27 & 7 & 4 & 1 & 2 & & 2 & & & & 79 \\
\hline Respiratory & 11 & 7 & & & 1 & 1 & & 1 & & & & 21 \\
\hline Other & 11 & 15 & 8 & & 1 & 4 & 1 & 2 & & 1 & & 43 \\
\hline TOTAL & 422 & 455 & 149 & 61 & 40 & 62 & 24 & 30 & 7 & 5 & & 1255 \\
\hline
\end{tabular}

$\mathrm{km})$. The distances referred to in this study are straight line distances. This method will result in an underestimate of distances between individual farms and corresponding slaughterhouses, as they do not take account of the actual road network or collection schedules. The authors conducted a small case study (unpublished) which compared straight line distance to actual road distance, the typical driving distances are between 1.25 and 1.29 times greater than the distances presented in this study. A compromised locomotor system will unavoidably lead to further suffering during transport (Broom 2000; Tarrant \& Grandin 2000). It is impossible to load recumbent animals onto a truck without causing considerable stress (Grandin, 2001). The British Cattle Veterinary Association (BCVA) in their 2005 guidance document recommend that in order to be transported, an animal must be able to bear weight on all four limbs.

Acute pain is emphasized as a defining factor when deciding whether an animal can be transported or not. In the current study, given our definition of emergency slaughter, $63.6 \%$ of the study animals were suffering acute pain (Table 2). While bone fractures are clearly a cause of acute pain, other injuries are also relevant to the present discussion. For example, lameness, which accounted for $12.9 \%$ of the injuries/disabilities associated with the locomotory system, causes pain (Webster 2005). Arthritic joints, infected foot lesions, tendon and ligament injuries, and other painful conditions are reasons for not transporting animals (British Cattle Veterinary Association 2005). In cases of chronic pain, stimuli are perceived to be more painful than would be normal. High levels of inflammatory mediators around the site of injury and the persistent activation of pain fibre pathways in the spinal cord each lead to a decrease in pain threshold (Hudson et al. 2008).

VCs were written throughout the year, with some monthly/ seasonal differences in different classes and production types. At the beginning and end of the livestock overwintering period (November and March-April), there tends to be an increase in the ES/CS of steers (Figure 3). This would coincide with a period of increased cattle movement for sales and movement of cattle into and out of houses, and the resulting mixing of animals from different sources. An increase in the ES/CS of bulls was noted during May, linked with the breeding season and movement for sale. Most ES/CS occurred early in the working week 
(Figure 4), which may reflect slaughterhouse availability and work practices. Animals issued with a VC on a Friday may not be slaughtered until the following Monday. However, animal welfare must be a priority in the decision-making process; if waiting would lead to further suffering, then the decision should be made to euthanase the animal. In the present study, the VC provided for ES and CS animals did not define the period of its validity. The time elapsed between veterinary certification and actual slaughter was greater than three days for $18.2 \%$ of all study animals (Table 2) and there were several cases of particular concern, including a delay of 23 days for an animal with a fractured hip, 11 days with a fractured foreleg and 8 days with a fractured tibia. These delays are unacceptable, and may reflect reluctance on the part of some owners/keepers to make timely and decisive decisions regarding culling and euthanasia. This issue might be most-effectively addressed if the VC were to include a section defining the period of its validity. A number of issues relating to ES/CS are of direct relevance to consumers, and to food safety. Stress during transport can result in latently infected animals shedding large numbers of pathogens (Collins \& Wall 2004). Stull et al. (2007) found that E. coli 0157:H7 in faecal or tissue samples was 3.3 times greater among downer cows arriving at slaughterhouses compared to normal cattle (an incidence of $4.9 \%$ versus $1.5 \%$, respectively). Transportation can also have a deleterious effect on product quality (Borell \& Schaffer 2005). There is also increasing public commitment to animal welfare, which has resulted in changes to EU policy and legislation in the area (Blokhuis et al. 2008). The public's perception of animal welfare has an increasing influence both on policy and food sales (Horgan \& Gavinelli 2006). Martin (2008) reported that the largest recall of beef in the history of the United States took place in 2008 as a direct result of the animal welfare abuses associated with the slaughter of downer cows in slaughterhouses.

Cattle in Ireland are food producing animals, and ES/CS has provided a mechanism to allow farmers to salvage some monetary value from injured animals. In taking this option, farmers see the benefit of sending ES/CS bovines to a slaughterhouse to be greater than the probability or risk of condemnation (White \& Moore 2009). In addition, the cost of any alternatives, such as veterinary treatment, euthanasia or knackery disposal, increases the incentive to transport the animal to the slaughterhouse. Until very recently in Ireland, there was no suitable alternative available to cattle producers wanting to salvage an otherwise healthy animal that had met with an accident or injury resulting in acute pain. Miller (2006) makes the point that salvage value should promote good animal welfare in that animals will be slaughtered before a problem escalates. This is particularly applicable in the case of older non-ambulatory animals; they should be culled before they become too weak and thin (Grandin 2001).

The first step in changing present management practices of ES/CS animals must be to make all of the stakeholders aware of their legal and moral obligation towards the welfare of the animals concerned. Webster (2005) reported that there is widespread belief that cattle are relatively insensitive to pain. This belief is based on the observation that cattle often do not seem to display the signs of distress that we would expect when in pain. In nature, cows and other ruminants are prey animals that live as herds in order to reduce individual risk of attack from predators. Exhibiting overt signs of distress and pain would increase the risk of predation. Such natural behaviour will mask underlying pain. This tendency to suffer in silence should be recognised by veterinarians and producers (O'Callaghan et al. 2003; Whiting 2004). In accordance with the policy of Veterinary Ireland, Ireland's national veterinary representative organisation, the capacity of animals to experience pain is no longer a matter of debate; absence of evidence of pain should not be surmised from the stoic behaviour that is typical of most ruminants (Anon, 2009). On farm awareness and a focus on prevention can each help to reduce accidents and avoid injury. Thomsen \& Sorensen (2009) highlight the problem of accidents due to machinery, poor design of slatted units/cubicle housing, and improper management of dystocias. White \& Moore (2009), in their slaughterhouse-based study of cow carcase condemnations, identified animal welfare concerns and potential production losses, and recommended the implementation of prevention practices on farms and feedlot by identifying critical control points. Stull et al. (2007) recommended on-farm management practices to reduce the incidence of downers. More care is required on farm with the use of machinery and the design and maintenance of slat and cubicle houses, there needs to be earlier veterinary intervention of sick or injured animals, and there is also a need for training of farmers, livestock handling staff and transporters. Based on a range of written comments on the VCs in the current study, it is clear that these recommendations are also applicable to Ireland. The incidence of ES/CS animals could be reduced if more care was taken when handling livestock and operating farm machinery. Quality assurance scheme operators should advise and promote proactive management of animals that are no longer economically viable so that they are disposed of before they endure unnecessary suffering. Veterinarians must be prepared to make a professional judgement on suitability for transport, on-farm slaughter or advise immediate euthanasia. The 
need for professional development training in animal welfare for veterinarians is recognised throughout Europe. During a Federation of Veterinarians of Europe (FVE) workshop at the General Assembly in November 2009, Bonafos (2009) suggested that 'Animal welfare is part of your oath and should be part of your education'. The workshop showed that although veterinarians have the potential and motivation to be the best placed profession in the field of animal welfare, they need specific training to do so. The FVE (2007) stated that the veterinarian, in addition to being specifically trained to protect animal and public health, possesses the full range of knowledge and skills to assess animal welfare, to identify the causes of poor welfare and to make recommendations for its correction. Hudson et al. (2008) reports that attitudes towards pain and its control in farm animals have lagged behind those in companion animals, and that a recent survey of cattle veterinary practitioners revealed that their knowledge of pain in cattle was inadequate.

During 2009, DAFF introduced an on-farm emergency slaughter policy (FAWAC 2009). Animals that have suffered an accident resulting in acute pain and are otherwise healthy can be slaughtered and bled on the farm without undue delay. Over $60 \%$ of the animals in the present study were designated emergency slaughter, and may therefore have been slaughtered on-farm had this option been available at the time. It is vital that the supportive structures are put in place to facilitate on-farm slaughter. For example, the provision of mobile slaughter units would facilitate the implementation of on-farm slaughter. Communication between all the stakeholders is essential. The welfare of the animals concerned must be given priority. Copies of both the VCs to accompany the carcase of a slaughtered animal, and the VC to accompany an ES/ CS animal, that is fit for transport to the slaughterhouse, should be made available online. All necessary data and guidelines should be readily accessible on line. Further, the VCs must incorporate a short period of validity, which should be legally binding. The cost of the on-farm slaughter should be such as not to deter the use of this option. It is important that all geographical areas are adequately served by participating slaughterhouses.

During the period of this study, there was no economically viable alternative available to farmers when faced with an injured animal. This fact never justified the extent to which the welfare of some animals was compromised in order to get the animal into the food chain. Given this context, it is clear that in most cases, once a decision was made to slaughter injured animals for human consumption, this was done as soon as possible. However, in a number of cases there was a failure to slaughter the animals without undue delay after the VC was provided. This would not have occurred if a legally binding period of validity had been stipulated on the VC's. Veterinarians frequently provided VCs for animals that were unfit to travel. Efforts must be made to urgently address these issues. The option of on farm slaughter is now available. The veterinary profession must utilise their professional skills and knowledge with regard to the recognition and management of speciesspecific pain in order to maximise animal welfare standards associated with emergency and casualty slaughter.

\section{ACKNOWLEDGEMENTS}

We thank the DAFF veterinary inspectors who provided copies of the veterinary certificates for this study. We also gratefully acknowledge Michael Sheridan's (DAFF) support and encouragement throughout this project and the statistical input from Tracy Clegg (CVERA).

\section{REFERENCES}

\section{Published literature}

Anon (2009) Veterinary Ireland Policy: Pain control in farm animals. Available at www.veterinaryireland.ie

Blokhuis, H.J., Keeling, L.J., Gavinelli, A. et al. (2008) Animal welfare's impact on the food chain. Trends in Food Science \& Technology 19, S79-S87.

Bonafos, L. (2009) Addressing a workshop during the FVE General Assembly 13-14 November 2009. Federation of Veterinarians of Europe Newsletter, December 2009. Available at http://www.fve.org/news/ newsletters/2009_5_newsletter.pdf

Borrell, E von and Schaffer, D. (2005) Legal requirements and assessment of stress and welfare during transportation and preslaughter handling of pigs. Livestock Production Science, 97 81-87

Broom, D.M. (2000) Welfare assessment and welfare problem areas during handling and transport. Ch. 4, In Livestock handling and transport, 43-61, $2^{\text {nd }}$ Ed., Grandin, T. (editor), CABI Publishing, United Kingdom.

Broom, D.M., Corke, M.J. (2002) Effects of disease on farm animal welfare. Acta Veterinaria Brno 71, 133136.

British Cattle Veterinary Association (2005) Guidance for veterinary surgeons and farmers on the slaughter of cattle which are injured or showing signs of abnormalities. British Cattle Veterinary Association Office, Gloucestershire, United Kingdom.

Collins, J.D., Wall, P.G. (2004) Food safety and animal productions systems: controlling zoonoses at farm level. Revue scientifique et technique (International Office of Epizootics) 23, 685-700.

DAFF (2007) CMMS Statistics Report 2006, Department of Agriculture, Fisheries and Food, National Beef Assurance Division. Available at http:// 
www.agriculture.gov.ie/animalhealthwelfare/

animalidentificationmovement/cattle/

DAFF (2008) CMMS Statistics Report 2007, Department

of Agriculture, Fisheries and Food, National

Beef Assurance Division. Available at http://

www.agriculture.gov.ie/animalhealthwelfare/

animalidentificationmovement/cattle/

DAFF (2009a) AIM Bovine Statistics Report 2008,

Department of Agriculture, Fisheries and Food,

National Beef Assurance Division. Available at

http://www.agriculture.gov.ie/animalhealthwelfare/

animalidentificationmovement/cattle/

DAFF (2009b) Bovine welfare at DAFF approved beef slaughter establishments. Beef meat standard operating procedure No. 2/2006 Rev 01 issue date 29/10/2009. Department of Agriculture, Fisheries and Food.

FAWAC (2009) Animal welfare guidelines for managing acutely injured animals on farm. Farm Animal Welfare Advisory Council booklet, July 2009. Available at http://www.fawac.ie/publications/AW_ GuidelinesManagaingAccutelylnjuredLivestock.pdf

FVE (2007) Welfare of animals at slaughter and killing - a new regulation. FVE/06/doc/033 Final (25/10/2007) Available at http://ec.europa.eu/food/animal/welfare/ slaughter/fve_new_reg_en.pdf

DG SANCO (2008) Report on a specific audit carried out in Ireland from 08/09/2008 to $12 / 09 / 2008$ in order to evaluate the implementation of controls for animal welfare on farms, during transport and the time of slaughter. Part B - sector specific issues. DG(SANCO)/2008-7768-Final.

Grandin, T. (1997) Assessment of stress during handling and transport. Journal of Animal Science 75, 249-257.

Grandin, T. (2001) Perspectives on transportation issues: the importance of having physically fit cattle and pigs. Journal of Animal Science, 79, E201-E207.

Horgan R., Gavinelli A. (2006) The expanding role of animal welfare within EU legislation and beyond. Livestock Science 103, 303-307.

Hudson, C., Whay, H., Huxley, J. (2008) Recognition and management of pain in cattle. In Practice 30, 126-134.

Kozak, A., Holejsovsky, J., Belobradek, P., et al. (2004) Emergency slaughter of pigs due to immobility. Veterinární medicína - Czech 49, 359-364.

Martin, A. (2008) Largest recall of ground beef is ordered. The New York Times 18/02/2008. Available at www. nytimes.com/2008/02/18/business/18recall.html

Miller, N. (2006) Provisions for emergency slaughter of cattle. The Veterinary Record 158:454 (letter).

O'Callaghan, K.A., Cripps, P.J., Downham, DY. et al. (2003) Subjective and objective assessment of pain and discomfort due to lameness in dairy cattle. Animal Welfare 12, 605-610.

Pistekova, V., Ostadalova, I., Sedlakova, J. et al. (2004) Emergency slaughter of cattle due to immobility. Acta Veterinaria Brno 73, 533-538.

Roman, B. (2009) Professional ethics and business ethics: a complex and necessary relationship in veterinary medicine. European Journal of Companion Animal Practice 19, 43-47.

Scientific Committee on Animal Health and Welfare (2001) The welfare of cattle kept for beef production. SANCO.C.2/AH/R22/2000, 1-150. Available at http:// ec.europa.eu/food/fs/sc/scah/out54_en.pdf

Stull, C.L., Payne, M.A., Berry, S.L., et al. (2007) A review of the causes, prevention and welfare of nonambulatory cattle. Journal of the American Veterinary Medical Association 231, 227-234.

Tarrant, V., Grandin, T. (2000) Cattle transport. Ch. 9, In Livestock handling and transport, 151-173, $2^{\text {nd }} \mathrm{Ed}$., Grandin, T. (editor), CABI Publishing, United Kingdom.

Thomsen, P.T., Sorensen, J.T. (2009) Factors affecting the risk of euthanasia for cows in Danish dairy herds. Veterinary Record 165, 43-45.

Vecerek, V., Bartosek, B., Kozak, A, et al. (2003) Emergency slaughter of cattle in the Czech Republic: the most frequent causes and their occurrence in the period of 1997-2002. Acta Veterinaria Brno 72, 445452.

Whiting, T.L. (2004) Application of the ethical matrix in evaluation of the question of downer cattle transport. Proceedings: Can West Veterinary Conference, Oct. ${ }^{\text {nd }}$.$5^{\text {th }}$. 2004. Available at: http://www.afac.ab.ca/ careinfo/transport/articles/twhitingdowner.pdf

Webster, J. (2005) Animals for food: cattle and other ruminants. Ch. 6, In Animal Welfare Limping Towards Eden, 130-156, $2^{\text {nd }}$ Ed., Blackwell Publishing, United Kingdom.

White, T.L., Moore, D.A. (2009) Reasons or whole carcass condemnations of cattle in the United States and implications for producer education and veterinary intervention. Journal of the American Veterinary Medical Association 235, 927-941.

\section{RELEVANT LEGISLATION}

\section{European legislation}

Council Directive 93/119/EC (1993) on the protection of animals at the time of slaughter or killing. Official Journal of the European Union L340, 0021-0034. Available at http://eur-lex.europa.eu/LexUriServ/ LexUriServ.do?uri=CELEX:31993L0119:EN:HTML

Council Regulation (EC) 1/2005 (2005) on the protection of animals during transport and related operations and amending Directives 64/432/EEC and 93/119/EC and 
Regulation (EC) No 1255/97. Official Journal of the European Union L003, 1-44. Available at http://eur-lex. europa.eu/LexUriServ/LexUriServ.do?uri=OJ:L:2005:00 3:0001:0044:EN:PDF

Regulation (EC) 852/2004 (2004) of the European Parliament and of the Council, on the hygiene of foodstuffs. Official Journal of the European Union L139, 1-54. Available at http://eur-lex.europa.eu/LexUriServ/ LexUriServ.do?uri=0J:L:2004:139:0001:0054:EN:PDF Regulation (EC) 853/2004 (2004) of the European Parliament and of the Council, on laying down specific hygiene rules for on the hygiene of foodstuffs. Official Journal of the European Union L139, 55-205. Available at http://eur-lex.europa.eu/LexUriServ/LexUriServ.do? uri=OJ:L:2004:139:0055:0205:EN:PDF

Regulation (EC) 854/2004 (2004) of the European Parliament and of the Council, on laying down specific rules for the organisation of official controls on products of animal origin intended for human consumption. Official Journal of the European Union L139, 206-320. Available at http://eur-lex.europa.eu/ LexUriServ/LexUriServ.do?uri=0J:L:2004:139:0206:03 20:EN:PDF

Regulation (EC) No. 882/2004 of the European Parliament and of Council, on official controls performed to ensure the verification of compliance with feed and food law, animal health and animal welfare rules. Official Journal of the European Union L155, 206-321. Available at: http://eur-lex.europa.eu/LexUriServ/LexUriServ.do?uri =OJ:L:2004:139:0206:0320:EN:PDF

\section{Irish legislation}

The Protection of Animals Act 1911. Available at: http:// www.irishstatutebook.ie

S.I. 675 of 2006; EC (Animal Transport and Control Post) Regulations 2006. Available at: http://www. irishstatutebook.ie/2006/en/si/0675.html

S.I. 14 of 2008; EC (Welfare of Farmed animals) Regulations 2008. Available at: http://www. irishstatutebook.ie/2008/en/si/0014.html

S.I. No. 910 of 2005: European Communities (Food and Feed Hygiene) Regulations 2005. Available at: http:// www.irishstatutebook.ie/2005/en/si/0910.htm 